\title{
Physical Restraint and Associated Factors in Adult Patients in Intensive Care Units: A Cross-sectional Study in North of Iran
}

\author{
Mahin Nomali ${ }^{1} \odot$, Aryan Ayati $^{2} \odot{\text { Mohammad } \text { Yadegari }^{3} \odot \text {, Mahdis Nomali }}^{4} \odot$ Mahnaz Modanloo $^{5} \odot$
}

\begin{abstract}
Background/aim: Patients in the intensive care units (ICUs) are at high risk of developing delirium and agitation. Physical restraint (PR) has increased to control these patients which accompanies by adverse consequences. The aim was to determine the PR use and associated factors in patients hospitalized at the ICUs in the North of Iran.

Materials and methods: In this cross-sectional study, a total of 272 patients in 3 ICUs of 5 Azar referral hospital affiliated to Golestan University of Medical Sciences (Gorgan, Iran) in 2018 were included. Confusion assessment method for the ICU (CAM-ICU), Richmond Agitation-Sedation Scale (RASS), acute physiology and chronic health evaluation II (APACHE II), and Glasgow Coma Scale (GCS) were used to evaluate delirium, sedation level, disease severity, and level of consciousness, respectively. Analysis was done by STATA version 14.2 (StataCorp LP, College Station, Texas), univariate and multiple analyses.

Results: Data from 272 patients were analyzed (mean age of $45.8 \pm 21.3$ years). PR was used for $74.5 \%$ of patients. Restrained patients had more severe disease [mean of APACHE II score, 20.20 (7.5) vs 11.6 (7.1)], longer length of stay [mean of 10 (5.5) vs 5.5 (4.6) days], and lower level of consciousness [mean of GCS score, 8.7 (3.5) vs 13.5 (3.3)] than patients without it. CAM-ICU was positive in majority of patients (79.5 vs $10.4 \%$ ) and agitation level of RASS score was higher in restrained patients (31.7 vs 3.0\%). Associated factors in multiple analysis were use of sedative and psychoactive drugs [odds ratio (OR), 2.85; 95\% confidence interval (Cl): 1.04-7.82], presence of delirium (OR, 15.13; 95\% Cl: 4.61-49.65), deep sedation (OR, 0.04; $95 \% \mathrm{Cl}: 0.00-0.45)$, and GCS score (OR, 0.69; $95 \% \mathrm{Cl}: 0.53-0.9)$.

Conclusion: This study revealed the high use of PR in the ICUs, and use of sedative and psychoactive drugs, presence of delirium, deep sedation, and GCS score were such associated factors.

Keywords: Critical care, Intensive care, Intensive care unit, Physical restraint.

Indian Journal of Critical Care Medicine (2022): 10.5005/jp-journals-10071-24103
\end{abstract}

\section{INTRODUCTION}

Patients admitted to intensive care units (ICUs) are at high risk of developing delirium and agitation due to medical conditions, multiple body system insufficiency, and the use of sedatives. ${ }^{1}$ The intensive care environment itself can cause stress and agitation because of the use of mechanical ventilation, invasive procedures, pain, fear, anxiety and excessive sensory stimuli, and sleep cycle disorders. ${ }^{2}$ In order to control these patients, the tendency to use physical restraint (PR) in these wards has increased. ${ }^{3}$ Although it seems to be a useful and simple solution to prevent treatment interference, it is in fact a complex concept that encompasses moral, legal, psychological, and physical issues. ${ }^{3}$

The prevalence of PR in the ICU varied between zero and $100 \%$ in different countries. ${ }^{4-8}$ In a qualitative study on nurses' perceptions toward PR, PR was considered as a key strategy for controlling patients that, despite its negative consequences, was widely used..$^{9}$ In 2015, Moradimajd et al. showed that PR is applied at the lowest standards in ICUs ${ }^{10}$ and is associated with adverse outcomes such as delirium, posttraumatic stress disorder (PTSD), higher rates of self-extubation, and longer hospital stay. ${ }^{11-13}$

Therapeutic, hospital, and patient profiles are among the predictors of the use of PR. In a study in Canada in 2014, treatment profiles, in contrast to hospital and patient profiles, predicted the use of PR and the number of days used. ${ }^{14}$ On the contrary, the reason for PR can be related to the patient (e.g. patient's age and diagnosis). Elderly patients with neurological and respiratory disorders usually need more restraint than other patients. PR use can also be related to the nurses in a way that older nurses, more qualified and more
${ }^{1}$ Department of Epidemiology and Biostatistics, School of Public Health, Tehran University of Medical Sciences, Tehran, Iran; Student Research Center, School of Public Health, Tehran University of Medical Sciences, Tehran, Iran

${ }^{2}$ School of Medicine, Tehran University of Medical Sciences, Tehran, Iran ${ }^{3}$ Bandar-e gaz Shohada Hospital, Golestan University of Medical Sciences, Gorgan, Iran

${ }^{4}$ Alejalil Hospital, Golestan University of Medical Sciences, Gorgan, Iran ${ }^{5}$ Nursing Research Center, Faculty of Nursing and Midwifery, Golestan University of Medical Sciences, Gorgan, Iran

Corresponding Author: Mahnaz Modanloo, Nursing Research Center, Faculty of Nursing and Midwifery, Golestan University of Medical Sciences, Gorgan, Iran, Phone: +01732456900; +989112739242, e-mail: modanloo.mahnaz@goums.ac.ir

How to cite this article: Nomali $M$, Ayati A, Yadegari $M$, Nomali $M$, Modanloo M. Physical Restraint and Associated Factors in Adult Patients in Intensive Care Units: A Cross-sectional Study in North of Iran. Indian J Crit Care Med 2022;26(2):192-198.

Source of support: Nil

Conflict of interest: None

experienced nurses have a better performance compared to other nurses. However, more studies are needed to identify the factors affecting the use of PR. ${ }^{15}$

Preventing the patient from falling off the bed and impairing the respiratory support have been reported as the main reasons 
for using PR by nurses in ICUs. ${ }^{16}$ Therefore, nurses may use PR to ensure patient safety, provide optimal nursing care, ${ }^{17}$ and prevent unplanned therapeutic interference that could lead to serious harm to the patient. There is a controversy in using this strait because of a moral dilemma contradicting the human values and respectful care, it could be also considered as a barbaric, cruel act and an obstacle to the patients' autonomy. ${ }^{18-22}$

Obstacles to reduce PR from the perspective of nursing staff include high workload, lack of resources, beliefs and concerns, lack of knowledge, differences and lack of integration, and communication issues. Design and use of clinical guidelines for PR, support for nursing staff in applying guidelines, providence of professional and clinical training, use of alternative devices, taking advantage of interdisciplinary approaches, and voluntary participation in the supportive care, such as employing more nurses to achieve a care without PR, can reduce the use of PR. ${ }^{23}$

Decisions about using PR in acute environments are often complex. Studies have shown that nurses are currently the main decision-makers in the use of PR in ICUs. ${ }^{17}$ In a study conducted in Spain, $94.1 \%$ of the PR was used by the nurses. ${ }^{24}$ In France, the usual lack of a physician prescription to start or stop using PR indicates that the decision to use PR is generally up to the nurse. ${ }^{6}$ In a mixedmethod study, all participants reported experiencing the use of PR that was primarily to ensure the patients' safety, while disagreeing on the benefits of PR. ${ }^{7}$ Therefore, given that the use of PR can be both for patient-related reasons and can be related to nurses, more studies are still needed. Since nurses are now the main decisionmakers to start and stop using PR in ICUs and considering the disagreement about the benefits of PR, it is necessary to conduct a study to investigate the extent and the reasons behind this problem in order to plan to reduce the use of PR in ICUs and identify the reasons for using it by the treatment team. Therefore, this study aimed to determine the use of PR and associated factors in patients hospitalized at the ICUs in the North of Iran.

\section{Materials and Methods}

\section{Study Design and Setting}

This was a cross-sectional study that was approved by the Institutional Review Board (IRB) (\#951224307) and the Research Ethics Committee (REC) (\#IR.GOUMS.REC.1396.10) of Golestan University of Medical Sciences (GoUMS, Gorgan, Iran), on April 30, 2017.

This study was carried out in the three ICUs of 5 Azar Hospital, a referral and tertiary hospital affiliated to GoUMS, including two medical surgical ICUs and one burn ICU with 14, 8, and 6 beds and admission range of $60-80,30-40$, and $30-40$ patients/month, respectively. It should be noted that in all three of these ICUs, the nurse-to-patient ratio was 1:2 with a greater majority of the nurses being female $(85,87$, and $69 \%$, respectively) and with an academic master $(79,87$, and $92 \%$, respectively). There were resident physicians in all three wards.

The study results have been reported according to strengthening the reporting of observational studies in epidemiology (STROBE) statement. $^{25}$

\section{Participants}

In this study, a total of 272 patients admitted to ICUs from both genders with an age of 18 or older were included from March 21 to September 22, 2018. Eligible patients were included by consecutive sampling and the recruitment was stopped after reaching the planned sample size.

\section{Variables}

Study variables were according to the related literature that included demographic factors, such as age and gender, and clinical factors, such as ICU length of stay, diagnosis, disease severity by "acute physiology and chronic health evaluation II" (APACHE II), use of sedative and psychoactive drugs, level of sedation by the Richmond agitation and sedation scale (RASS), delirium by the confusion assessment method for ICU (CAM-ICU) score, level of consciousness by Glasgow Coma Scale (GCS) score, ability to communicate, PR usage in the last 24 hours, the kind of material used for the restraint, type of restraint, time of the day that the restraint was mostly used, patients' evaluation after the restraint and type of evaluation, duration of restraint, documented physician's order for restraint, documentation of PR in the nursing report, the patient group, and the reason for PR usage.

\section{Data Measurement}

The study form was completed according to the patient's clinical record and standard scales. In order to assess the delirium, the CAM-ICU scale was used. This scale consisted of four features including (1) altered mental status/fluctuating course, (2) inattention, (3) altered level of consciousness, and (4) disorganized thinking. Based on the answers, the result can indicate the existence of delirium. A valid and reliable (Cronbach's alpha $=88.0$ ) version of this tool in the Farsi language provided by Mansouri et al. ${ }^{26}$ was used in the first 24 hours of ICU admission. It should be noted that before delirium assessment, the patients' level of sedation was determined by the RASS. ${ }^{27}$

RASS was used to assess the level of sedation. It consists of 10 scores between -5 and +4 including -5 for unarousable, -4 for deep sedation, -3 for moderate sedation, -2 for light sedation, -1 for drowsy, 0 for alert and calm, 1 for restless, 2 for agitated, 3 for very agitated, and 4 for a combative state. A score of 3 or higher is assessed as delirium. ${ }^{28}$ Then it was categorized to light sedation (score of -2 to +1 ), deep sedation (score of -3 to -5 ), and agitation (score of +2 to +4 ). ${ }^{29} \mathrm{~A}$ Farsi version of RASS was translated by Tadrisi et al. with a correlation coefficient of 0.95 between RASS and Visual Analog Scale (VAS) scores. This tool demonstrated an acceptable reliability and validity for utilization in ICUs to evaluate the level of sedation and agitation. ${ }^{30}$

To determine the disease severity, the form related to APACHE II scale that was revised in 1999 and translated into the Farsi language by Ramazani and Hosseini ${ }^{31}$ was completed for each patient. This scale indicated the disease severity at the time of admission and the first 24 hours. This scale, which was designed by Knaus et al., is used to classify disease severity and consisted of three different parts: The first part is the acute physiologic score and has 12 parameters. Eleven parameters were defined in specific ranges from the normal values. Each range has a specific score (from 0 to 4 ) based on the difference from the normal range. The 12th parameter is the level of consciousness based on the GCS. A normal GCS score (score of 15) subtracted by the patient's GCS score formed the 12th parameter and in sum with other parameters, the acute physiologic score was obtained. The second and third parts are chronic diseases and age score and together with the acute physiologic score, they form an APACHE II total score between 0 and 71. A higher score indicates an increased severity and hospital mortality. ${ }^{32}$ 


\section{Study Size}

The sample size was calculated according to the sample size formula $n=\left(z_{1-\alpha / 2}\right) 2 p(1-p) / d^{2}$, prevalence of $23 \%$ for physical restraint usage in the van der Kooi et al. $\operatorname{study}^{33}(p=23.0)$, a 5\% type I error, $d$ of 0.05 , and a $95 \%$ confidence level $(\mathrm{Cl})$.

\section{Statistical Methods}

Data were analyzed by STATA version 14.2 (StataCorp LP, College Station, Texas). Categorical variables were reported as numbers and percentages and continuous variables were reported as mean (SD) or median [interquartile range (IQR)]. Univariate logistic regression was run and variables with $p$ value less than 0.2 were entered to the multiple logistic regression model. Odds ratio (OR) with $95 \%$ of $\mathrm{Cl}$ were reported and a $p$ value less than 0.05 was considered as statistically significant.

\section{Results}

\section{Participants}

Data from 272 patients admitted to ICUs of the study setting were analyzed (mean age of 45.8 years, SD 21.3 years, and $64.7 \%$ male).

\section{Main Results}

PR was used for an overall number of 205 patients (74.5\%). The characteristics of the used PR have been demonstrated in Table 1. According to the table, roll gauze was the most common material (97.1\%) and four limbs restraint was the most common method $(75.6 \%)$ used for the restraint. For the majority of patients $(72.2 \%)$, the restraint was used based on their condition. For $99.5 \%$ of patients, an assessment was done subsequent to the restraint. Examination of distal pulse and color was the most common type of assessment (99.0\%). A physician's order for PR was documented for only $29.8 \%$ of the patients, while $83.9 \%$ of the restraints were documented in the nursing report. Patients with delirium were the majority group (79.5\%) who underwent a restraint. Patients' fall prevention was the most reported cause (82.0\%) for PR (Table 1).

Frequency distribution of PR according to demographic and clinical factors of the study patients has been demonstrated in Table 2. According to this table, the age-group of 44 and higher and the male gender had a higher frequency of PR. In addition to that, the mean of ICU length of stay and disease severity score was higher in patients with PR. Majority of restrained patients had a nonsurgical diagnosis and used psychoactive and sedative drugs. CAM-ICU was positive in majority of patients with PR and most of these patients were unable to communicate and had several connections. Furthermore, agitation level of RASS was higher in restrained patients (31.7 vs 3.0\%), while mean GCS score was lower in patients with restraint (Table 2 ).

The results of univariate and multiple analyses have been indicated in Table 3. Multiple analysis indicated that use of sedative and psychoactive drugs, presence of delirium (positive score of CAM-ICU), deep sedation, and GCS score were such associated factors (Table 3).

\section{Discussion}

This study was conducted in order to determine the frequency of PR usage and its associated factors in ICUs of 5 Azar tertiary hospital affiliated to GoUMS in 2018. The data indicated that PR was used for $74.5 \%$ of ICU patients. PR usage was reported by $68 \%$ of nurses who worked in adult ICUs in Egypt ${ }^{34}$ and it was $61.2 \%$ in Chinese ICUs. ${ }^{35}$ On the contrary, the PRICE study indicated PR use in ICUs across Europe with a range of zero in the United Kingdom and Portugal to $100 \%$ in Italy. In addition, PR usage was $12 \%$ in Finland, $21 \%$ in Greece, $28 \%$ in Israel, $45 \%$ in Spain, $43 \%$ in Switzerland,

Table 1: Characteristics of the used physical restraint

\begin{tabular}{|c|c|}
\hline Characteristics & $\begin{array}{c}\text { Number (percent) } \\
(n=205)\end{array}$ \\
\hline \multicolumn{2}{|c|}{ Type of material used for restraint } \\
\hline Roll gauze & $199(97.1)$ \\
\hline Specific restraints & $6(2.9)$ \\
\hline \multicolumn{2}{|l|}{ Type of physical restraint } \\
\hline Four limbs restraint & $155(75.5)$ \\
\hline Wrist restraint & $43(21.0)$ \\
\hline Ankle restraint & $2(1.0)$ \\
\hline Restraint of a wrist & $3(1.5)$ \\
\hline Bedside & $2(1.0)$ \\
\hline \multicolumn{2}{|l|}{ Time to use restraint } \\
\hline 8 am to $4 p m$ & $1(0.5)$ \\
\hline $4 \mathrm{pm}$ to $8 \mathrm{am}$ & $56(27.3)$ \\
\hline $\begin{array}{l}\text { Depending on the } \\
\text { patient's condition }\end{array}$ & $148(72.2)$ \\
\hline \multicolumn{2}{|c|}{ Evaluation of the patient after the use of restraint } \\
\hline Yes & $204(99.5)$ \\
\hline No & $1(0.5)$ \\
\hline \multicolumn{2}{|l|}{ Evaluation type } \\
\hline Skin color & $1(0.5)$ \\
\hline Distal pulse & $1(0.5)$ \\
\hline Distal pulse and color & $203(99.0)$ \\
\hline $\begin{array}{l}\text { Duration of restraint } \\
\text { during ICU stay [median } \\
\text { (IQR)] (hours) }\end{array}$ & $6.0(6.0)$ \\
\hline \multicolumn{2}{|c|}{ Doctor's written order to restraint } \\
\hline Yes & $61(29.8)$ \\
\hline No & $144(70.2)$ \\
\hline \multicolumn{2}{|c|}{$\begin{array}{l}\text { Documentation of physical restraint in nursing } \\
\text { report }\end{array}$} \\
\hline Yes & $172(83.9)$ \\
\hline No & $33(16.1)$ \\
\hline
\end{tabular}

Patient group (patient may be placed in more than one group)

$\begin{array}{lr}\text { Agitated } & 82(40.0) \\ \text { Unconscious } & 70(34.1) \\ \text { Delirious } & 163(79.5) \\ \text { Recipient of sedatives } & 140(68.3) \\ \text { Connected to ventilator } & 118(57.6)\end{array}$

The reason for using restraint (more than one cause could be the reason for the use of restraint)

$\begin{array}{lc}\text { Pulling tubes and lines } & 118(57.6) \\ \begin{array}{l}\text { Prevention of tracheal } \\ \text { tube self-extubation }\end{array} & 141(68.8) \\ \begin{array}{l}\text { Patients fall prevention } \\ \text { Risk of harm to oneself }\end{array} & 168(82.0) \\ \text { or others } & 65(31.7) \\ \text { Unstable fracture } & 16(7.8) \\ \text { Delirium } & 163(79.5) \\ \text { Unknown reason } & 12(5.9)\end{array}$


Table 2: Frequency distribution of physical restraint in patients hospitalized in ICUs according to demographic and clinical factors of the study patients

\begin{tabular}{|c|c|c|c|}
\hline \multirow[b]{2}{*}{ Demographic and clinical factors } & \multirow[b]{2}{*}{$\begin{array}{c}\text { Total } \\
(n=272)\end{array}$} & \multicolumn{2}{|c|}{$\begin{array}{l}\text { Use of physical restraint } \\
\text { number (percent) }\end{array}$} \\
\hline & & $\begin{array}{c}\text { Yes } \\
(n=205)\end{array}$ & $\begin{array}{c}\text { No } \\
(n=67)\end{array}$ \\
\hline Age [Mean (SD)] (years) & $45.8(21.3)$ & $46.8(21.4)$ & $42.7(20.8)$ \\
\hline$<29$ & $70(25.7)$ & $54(26.3)$ & $16(23.9)$ \\
\hline $29-44$ & $69(25.4)$ & $47(23.0)$ & $22(32.8)$ \\
\hline$>44$ & $133(9.48)$ & $104(50.7)$ & $29(43.3)$ \\
\hline \multicolumn{4}{|l|}{ Gender } \\
\hline Male & $176(64.7)$ & $140(68.3)$ & $36(53.7)$ \\
\hline Female & $96(35.3)$ & $65(31.7)$ & $31(46.3)$ \\
\hline ICU length of stay [Mean (SD)] (day) & $8.9(5.6)$ & $10(5.5)$ & $5.5(4.6)$ \\
\hline \multicolumn{4}{|l|}{ Diagnosis } \\
\hline Medical & $134(49.2)$ & $104(50.7)$ & $30(44.8)$ \\
\hline Surgical & $138(51.1)$ & $101(49.3)$ & $37(55.2)$ \\
\hline Disease severity (APACHE II score) [Mean (SD)] & $18.1(8.2)$ & $20.2(7.5)$ & $11.6(7.1)$ \\
\hline \multicolumn{4}{|l|}{$\begin{array}{l}\text { Use of sedatives and } \\
\text { psychoactive drugs }\end{array}$} \\
\hline Yes & $182(66.9)$ & $155(75.6)$ & $27(40.3)$ \\
\hline No & $90(33.1)$ & $50(24.4)$ & $40(59.7)$ \\
\hline \multicolumn{4}{|l|}{ CAM-ICU } \\
\hline Positive & $170(62.5)$ & $163(79.5)$ & $7(10.4)$ \\
\hline Negative & $102(37.5)$ & $42(20.5)$ & $60(89.6)$ \\
\hline \multicolumn{4}{|l|}{ Sedation level (RASS score) } \\
\hline Light sedation & $123(45.2)$ & 65 (31.7) & $58(86.6)$ \\
\hline Deep sedation & $82(30.2)$ & 75 (36.6) & $7(10.4)$ \\
\hline Agitation & $67(24.6)$ & $65(31.7)$ & $2(3.0)$ \\
\hline Level of consciousness (GCS score) [Mean (SD)] & $9.8(4.0)$ & $8.7(3.5)$ & $13.5(3.3)$ \\
\hline \multicolumn{4}{|l|}{ Ability to communicate } \\
\hline Yes & $122(44.8)$ & $64(31.2)$ & $58(86.6)$ \\
\hline No & $150(55.2)$ & $141(68.8)$ & $9(13.4)$ \\
\hline \multicolumn{4}{|l|}{$\begin{array}{l}\text { Patient connections (patient can have more } \\
\text { than one connection) }\end{array}$} \\
\hline Feeding tube & $184(67.6)$ & $163(79.5)$ & $21(31.3)$ \\
\hline Urinary catheter & $245(91.0)$ & $199(97.1)$ & $46(68.7)$ \\
\hline Central vein catheter & $69(25.4)$ & $63(30.7)$ & $6(9.0)$ \\
\hline Peripheral vein catheter & $16(5.8)$ & $12(5.9)$ & $4(6.0)$ \\
\hline Arterial catheter & $5(1.8)$ & $5(2.4)$ & $0(0.0)$ \\
\hline
\end{tabular}

and $47 \%$ in France. ${ }^{4}$ The prevalence of PR usage also was $35.8 \%$ (33.3-57.1\%) in Jordan ${ }^{36}$ and $23 \%(0-56 \%)$ in Germany. ${ }^{24}$ In some regions in Europe, Africa, and Asia, variations in PR usage were lower than ours. In contrast, in Italy, it was higher than ours. The overall proportion of patients restrained physically in our study was higher than most previous studies. According to our knowledge, there is a lack of knowledge regarding PR usage in Iran's critical care settings in order to be compared with our findings which require further studies in different ICUs. The high PR usage may be due to the characteristics of the studied ICUs regarding nursing staffs and type of ICUs. A study in 2011 in Egypt indicated that the percentage of restrained patients increases with an increasing nurse-to-patient ratio and percentage of all restrained patients in the unit was 20 , 32 , and 50 for $1: 1,1: 2$, and 1:3 nurse-to-patient ratio, respectively. ${ }^{15}$
In our study, the nurse-to-patient ratio was 1:2 and preventing patients from falling, self-tube extubating, and pulling tubes and lines were the most important reasons for PR usage. On the contrary, this high usage may be due to the patients' clinical characteristics such as lower levels of consciousness, ${ }^{33}$ delirious condition, ${ }^{33,35,37}$ higher usage of sedative and psychoactive drugs, $4,33,35$ and deep sedation, which were significantly associated with PR use. As we stated earlier, our study setting was medical, surgical, and burn ICUs of a tertiary hospital which admitted more critical patients that need much more nursing cares. Thus, further studies are needed to conduct a subgroup analysis of type of critical care settings in order to compare results in different settings. PR usage in critical care settings results in different organizational, ethical, and emotional challenges for nurses. In order to reduce PR usage 
Physical Restraint in Intensive Care Units

Table 3: Factors associated with physical restraint in patients hospitalized in ICUs

\begin{tabular}{|c|c|c|c|c|}
\hline \multirow{2}{*}{$\begin{array}{l}\text { Demographic and clinical } \\
\text { factors }(n=272)\end{array}$} & \multicolumn{2}{|c|}{ Unadjusted } & \multicolumn{2}{|c|}{ Adjusted } \\
\hline & OR $(95 \% C l)$ & pvalue & OR $(95 \% \mathrm{Cl})$ & $p$ value \\
\hline Age (years) & $1.00(0.9-1.02)$ & 0.164 & $1.01(0.99-1.03)$ & 0.232 \\
\hline Male sex & $1.80(1.05-3.25)$ & 0.032 & $2.54(0.89-7.23)$ & 0.080 \\
\hline ICU length of stay (day) & $1.26(1.16-1.38)$ & $<0.001$ & $1.00(0.87-1.15)$ & 0.935 \\
\hline Surgical diagnosis & $1.27(0.72-2.20)$ & 0.398 & - & - \\
\hline Disease severity (APACHE II score) & $1.16(1.11-1.22)$ & $<0.001$ & $0.99(0.91-1.08)$ & 0.960 \\
\hline $\begin{array}{l}\text { Use of sedatives and psychoactive } \\
\text { drugs }\end{array}$ & $4.59(2.56-8.22)$ & $<0.001$ & $2.85(1.04-7.82)$ & 0.041 \\
\hline $\begin{array}{l}\text { Positive score of CAM-ICU (presence of } \\
\text { delirium) }\end{array}$ & $33.0(14.17-78.07)$ & $<0.001$ & $15.13(4.61-49.65)$ & $<0.001$ \\
\hline \multicolumn{5}{|l|}{ Sedation level (RASS score) } \\
\hline Light sedation & 1 & - & 1 & - \\
\hline Deep sedation & $9.56(4.07-22.40)$ & $<0.001$ & $0.04(0.00-0.45)$ & 0.009 \\
\hline Agitation & $29.0(6.79-123.74)$ & $<0.001$ & $2.23(0.33-14.89)$ & 0.405 \\
\hline Level of consciousness (GCS score) & $0.62(0.54-0.71)$ & $<0.001$ & $0.69(0.53-0.9)$ & 0.006 \\
\hline Ability to communicate & $0.07(0.03-0.15)$ & $<0.001$ & $0.19(0.03-1.11)$ & 0.066 \\
\hline \multicolumn{5}{|c|}{ Patient connections (patient can have more than one connection) } \\
\hline Feeding tube & $8.50(4.58-15.76)$ & $<0.001$ & $2.46(0.80-7.52)$ & 0.115 \\
\hline Urinary catheter & $15.14(5.78-39.63)$ & $<0.001$ & $4.19(0.69-25.27)$ & 0.118 \\
\hline Central vein catheter & $4.51(1.85-10.97)$ & 0.001 & $1.87(0.53-6.62)$ & 0.328 \\
\hline Peripheral vein catheter & $0.97(0.30-3.14)$ & 0.972 & - & - \\
\hline
\end{tabular}

and its subsequent challenges, strategies, including developing standard evidence-based guidelines, equipping hospital wards with standard equipment, implementing in-service educational programs, supervising nurses' practice, and empowering them for finding and using alternatives to physical restraint can be applied ${ }^{38}$ and their efficacy on the proportion of PR usage can be evaluated through clinical trial studies. PR was used for various reasons. In this study, the data suggested that in most of the cases, preventing patients from falling was the reason for using restraints. However, in a study by Langley et al., assuring the patients' safety was reported by nurses as the main reason for physical restraint. ${ }^{7}$ In a descriptive study by Minnick et al., preventing treatment interferences was reported as the cause for PR. ${ }^{16}$ These differences could be due to various environments and guidelines for PR which require further studies in different countries.

In this study, patients with an age of more than 44 had the most usage of PR, while age was not an associated factor with PR use which may be due to the almost similar frequency distribution among age-groups. In a study by Krüger et al., patients with an age-group of 80-99 years who underwent PR 4.32 times more than the 18-54 year age-group ${ }^{39}$ and age were considered as an independent risk factor. ${ }^{35}$

According to the present study, a greater number of the patients who underwent PR were male. However, male gender was not associated with PR usage and the borderline significance level was found. In a multi-central study conducted by van der Kooi et al., ${ }^{33}$ and in a study in China (2019), ${ }^{35}$ genders were not independently related to the prevalence of $\mathrm{PR}$.

In our study, ICU length of stay and disease severity score were not associated with PR usage. Similarly, in a multicenter study, disease severity was not independently related to PR. ${ }^{33}$ In contrast, in a study by Hofmann et al., hospital stay duration was positively related to the usage of $\mathrm{PR}^{40}$ and in a study by Krüger et al., ICU stay was related to usage of $\mathrm{PR} .{ }^{39}$

Our data revealed that the CAM-ICU score was positive in most of the restrained patients. Patients with delirium were the most common group with PR. The majority of patients who underwent PR were unable to communicate and used psychoactive and sedative drugs. In the study by van der Kooi et al., the risk of undergoing PR was higher in patients with either delirium or coma, who were unable to communicate or used psychoactive or sedative drugs. ${ }^{33}$

Most of the patients with PR had multiple points of restraint and were admitted with a nonsurgical diagnosis. In a descriptive study by Minnick et al., variables such as type of ward (adults medical ICU) and usage of mechanical ventilator were highly related to PR usage. Elderly patients were more likely to undergo PR in medical wards compared to other wards where PR was used for mostly nonelderly patients. ${ }^{16}$ Although the study was based on elderly patients, both studies were performed in ICUs and are in concordance with each other.

There were several limitations in this study. Because of being a single-center observational study, no causal association can be inferred from this study. Second, the study population was ICU patients and the study findings cannot be applied to patients hospitalized in other units.

Findings of this study demonstrated high usage of PR in studied ICUs. Use of sedative and psychoactive drugs, presence of delirium, deep sedation, and GCS score were such associated factors. Thus, there is a need to consider the PR policy and its application in the studied ICUs and evaluate the effect of its application through further interventional studies. 


\section{ACKnOWLedgments}

This article is derived from a research project (approval ID. 951224307) approved by Golestan University of Medical Sciences (GoUMS) (Gorgan, Iran). The authors thank the research and technology deputy of GoUMS and Clinical and Research Development Unit (CRDU) of 5 Azar hospital affiliated to GoUMS for the approval process and the study participants that made this research possible and the nursing staffs in the ICUs of the study setting for their collaboration.

\section{OrCID}

Mahin Nomali @ https://orcid.org/0000-0002-0773-4977

Aryan Ayati @ https://orcid.org/0000-0002-0241-6865

Mohammad Yadegari $\odot$ https://orcid.org/0000-0002-3504-4316

Mahdis Nomali ৫ https://orcid.org/0000-0002-7082-2099

Mahnaz Modanloo 으 https://orcid.org/0000-0002-8801-6653

\section{References}

1. Ely EW, Margolin R, Francis J, May L, Truman B, Dittus R, et al. Evaluation of delirium in critically ill patients: validation of the Confusion Assessment Method for the Intensive Care Unit (CAM-ICU). Crit Care Med 2001;29(7):1370-1379. DOI: 10.1097/00003246-200107000-00012.

2. Haskell RM, Frankel HL, Rotondo MF. Agitation. AACN Adv Crit Care 1997;8(3):335-350. DOI: 10.1097/00044067-199708000-00005.

3. Hine K. The use of physical restraint in critical care. Nurs Crit Care 2007;12(1):6-11. DOI: 10.1111/j.1478-5153.2006.00197.x.

4. Benbenbishty J, Adam S, Endacott R. Physical restraint use in intensive care units across Europe: the PRICE study. Intensive Crit Care Nurs 2010;26(5):241-245. DOI: 10.1016/j.iccn.2010.08.003.

5. Choi E, Song M. Physical restraint use in a Korean ICU. J Clin Nurs 2003;12(5):651-659. DOI: 10.1046/j.1365-2702.2003.00789.x.

6. De Jonghe B, Constantin J-M, Chanques G, Capdevila X, Lefrant J-Y, Outin $\mathrm{H}$, et al. Physical restraint in mechanically ventilated ICU patients: a survey of French practice. Intensive Care Med 2013;39(1):31-37. DOI: 10.1007/s00134-012-2715-9.

7. Langley G, Schmollgruber S, Egan A. Restraints in intensive care units-a mixed method study. Intensive Crit Care Nurs 2011;27(2): 67-75. DOI: 10.1016/j.iccn.2010.12.001.

8. Martin B, Mathisen L. Use of physical restraints in adult critical care: a bicultural study. Am J Crit Care 2005;14(2):133-142. PMID: 15728955.

9. Moghadam MF, Khoshknab MF, Pazargadi M. Psychiatric nurses' perceptions about physical restraint: a qualitative study. Int J Community Based Nurs Midwifery 2014;2(1):20. PMID: 25349842.

10. Moradimajd P, Noghabi AA, Zolfaghari M, Mehran A. Physical restraint use in intensive care units. Iran J Crit Care Nurs 2015;8(3):173-178.

11. Chang L-Y, Wang K-WK, Chao Y-F. Influence of physical restraint on unplanned extubation of adult intensive care patients: a case-control study. Am J Crit Care 2008;17(5):408-415. PMID: 18775996.

12. Jones C, Bäckman C, Capuzzo M, Flaatten H, Rylander C, Griffiths R. Precipitants of post-traumatic stress disorder following intensive care: role and need of physical restraints. Reply by authors to Dr Kapadia. Intensive Care Medicine 2007;33(12):2227. DOI: 10.1007/s00134-0070872-z.

13. Van RompaeyB,Elseviers MM, Schuurmans MJ, Shortridge-BaggettLM, Truijen S, Bossaert L. Risk factors for delirium in intensive care patients: a prospective cohort study. Crit Care 2009;13(3):R77. DOI: 10.1186/cc7892.

14. Luk E, Sneyers B, Rose L, Perreault MM, Williamson DR, Mehta S, et al. Predictors of physical restraint use in Canadian intensive care units. Crit Care 2014;18(2):R46. DOI: 10.1186/cc13789.

15. Al-Khaled T, Zahran E, El-Soussi A. Nurses' related factors influencing the use of physical restraint in critical care units. J Am Sci 2011;7(8): $13-22$.
16. Minnick AF, Mion LC, Johnson ME, Catrambone C, Leipzig R. Prevalence and variation of physical restraint use in acute care settings in the US. J Nurs Scholarsh 2007;39(1):30-37. DOI: 10.1111/j.1547-5069.2007.00140.x.

17. Li X, Fawcett TN. Clinical decision making on the use of physical restraint in intensive care units. Int J Nurs Sci 2014;1(4):446-450. DOI: 10.1016/j.ijnss.2014.09.003.

18. Evans D, Wood J, Lambert L. A review of physical restraint minimization in the acute and residential care settings. J Adv Nurs 2002;40(6):616-625. DOI: 10.1046/j.1365-2648.2002.02422.x.

19. Happ M, Kagan S, Strumpf N, Evans L, Sullivan-Marx E. Elderly patients memories of physical restraint use in the intensive care unit (ICU). Am J Crit Care 2001;10(5):367-369. DOI: 10.4037/ajcc2001.10.5.367.

20. Larson MJ, Weaver LK, Hopkins RO. Cognitive sequelae in acute respiratory distress syndrome patients with and without recall of the intensive care unit. J Int Neuropsychol Soc 2007;13(04):595-605. DOI: $10.1017 /$ S1355617707070749.

21. Reigle J. The ethics of physical restraints in critical care. AACN Adv Crit Care 1996;7(4):585-591. DOI: 10.1097/00044067-199611000-00014.

22. Wunderlich RJ, Perry A, Lavin MA, Katz B. Patients' perceptions of uncertainty and stress during weaning from mechanical ventilation. Dimens Crit Care Nurs 1999;18(1):2-12. PMID: 10639993.

23. Kong $\mathrm{E}-\mathrm{H}$, Evans LK. Nursing staff views of barriers to physical restraint reduction in nursing homes. Asian Nurs Res 2012;6(4):173-180. DOI: 10.1016/j.anr.2012.10.007.

24. Martín IV, Pontón SC, Quintián GM, Velasco ST, Merino MM, Simón GM, et al. [Mechanical restraint: its use in intensive cares]. Enferm Intensiva 2011;23(4):164-170. DOI: 10.1016/j.enfi.2012.08.002.

25. ElmEv, AltmanDG, Egger M,PocockSJ, GøtzschePC, VandenbrouckeJP. Strengthening the reporting of observational studies in epidemiology (STROBE) statement: guidelines for reporting observational studies. BMJ 2007;335(7624):806-808. DOI: 10.1136/ bmj.39335.541782.AD.

26. Mansouri P, Javadpour S, Zand F, Ghodsbin F, Sabetian G, Masjedi M, et al. Implementation of a protocol for integrated management of pain, agitation, and delirium can improve clinical outcomes in the intensive care unit: a randomized clinical trial. J Crit Care 2013;28(6):918-922. DOI: 10.1016/j.jcrc.2013.06.019.

27. Ely EW, Inouye SK, Bernard GR, Gordon S, Francis J, May L, et al. Delirium in mechanically ventilated patients: validity and reliability of the confusion assessment method for the intensive care unit (CAM-ICU). Journal of the American Medical Association 2001;286(21):2703-2710. DOI: 10.1001/jama.286.21.2703.

28. Sessler CN, Gosnell MS, Grap MJ, Brophy GM, O'Neal PV, Keane KA, et al. The Richmond Agitation-Sedation Scale: validity and reliability in adult intensive care unit patients. Am J Respir Crit Care Med 2002;166(10):1338-1344. DOI: 10.1164/rccm.2107138.

29. Shehabi Y, Bellomo R, Reade MC, Bailey M, Bass F, Howe B, et al. Early intensive care sedation predicts long-term mortality in ventilated critically ill patients. Am J Respir Crit Care Med 2012;186(8):724-731. DOI: $10.1164 / \mathrm{rccm} .201203-05220$.

30. Tadrisi S, Madani S, Farmand F, Ebadi A, Karimi ZA, Saghafinia M, et al. Richmond agitation-sedation scale validity and reliability in intensive care unit adult patients. Persian version; 2009.

31. Ramazani J, Hosseini M. The assessment of APACHE II scoring system in predicting the result of weaning from ventilator. J Knowledge Health Basic Med Sci 2014;8(4):187-192. DOI: 10.1234/knh.v8i4.433.

32. Knaus WA, Draper EA, Wagner DP, Zimmerman JE. APACHE II: a severity of disease classification system. Crit Care Med 1985;13(10):818-829. PMID: 3928249.

33. van der Kooi AW, Peelen LM, Raijmakers RJ, Vroegop RL, Bakker DF, Tekatli $\mathrm{H}$, et al. Use of physical restraints in Dutch intensive care units: a prospective multicenter study. Am J Crit Care 2015;24(6):488-495. DOI: 10.4037/ajcc2015348.

34. Kandeel NA, Attia AK. Physical restraints practice in adult intensive care units in Egypt. Nurs Health Sci 2013;15(1):79-85. DOI: 10.1111/ nhs. 12000 . 
35. Gu T, Wang X, Deng N, Weng W. Investigating influencing factors of physical restraint use in China intensive care units: a prospective, cross-sectional, observational study. Austr Crit Care 2019;32(3): 193-198. DOI: 10.1016/j.aucc.2018.05.002.

36. Suliman M. Prevalence of physical restraint among ventilated intensive care unit patients. J Clin Nurs 2018;27(19-20):3490-3496. DOI: $10.1111 /$ jocn.14588.

37. Mehta S, Cook D, Devlin JW, Skrobik Y, Meade M, Fergusson D, et al. Prevalence, risk factors, and outcomes of delirium in mechanically ventilated adults. Crit Care Med 2015;43(3):557-566. DOI: 10.1097/ CCM.0000000000000727.
38. Salehi Z, Joolaee S, Hajibabaee F, Ghezeljeh TN. The challenges of using physical restraint in intensive care units in Iran: a qualitative study. J Intensive Care Soc 2021;22(1):34-40. DOI: 10.1177/ 1751143719892785.

39. Krüger C, Mayer H, Haastert B, Meyer G. Use of physical restraints in acute hospitals in Germany: a multi-centre cross-sectional study. Int J Nurs Stud 2013;50(12):1599-1606. DOI: 10.1016/j.ijnurstu.2013. 05.005 .

40. Hofmann H, Schorro E, Haastert B, Meyer G. Use of physical restraints in nursing homes: a multicentre cross-sectional study. BMC Geriatr 2015;15(1):1. DOI: 10.1186/s12877-015-0125-x. 